\title{
RESUMO
}
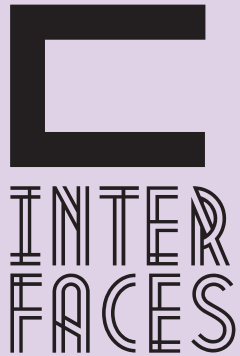

CIENTÍFICAS

\section{A POLĹTICA DE EXPANSÃO DO ENSINO SUPERIOR POR MEIO DA UAB EM ALAGOAS}

THE POLICY OF HIGHER EDUCATION EXPANSION THROUGH UAB IN ALAGOAS

\section{LA POLITIICA DE EXPANSIÓN DE LA ENSEÑANZA SUPERIOR POR MEDIO DE LA UAB EN ALAGOAS}

Fernando Silvio Cavalcante Pimentel ${ }^{1}$ Luís Paulo Leopoldo Mercado ${ }^{2}$
O estudo investiga a Universidade Aberta do Brasil (UAB) enquanto política pública de expansão da educação superior no estado de Alagoas, que visa ampliar o número de professores da educação básica com formação superior, como determina a Lei de Diretrizes e Bases da Educação Nacional e o Plano Nacional de Educação. Analisa o perfil dos estudantes da UAB na Universidade Federal de Alagoas (UFAL). 0 estudo de caso envolveu coleta de dados por meio de questionário on-line junto aos estudantes de 10 cursos de graduação ofertados. Os resultados mostram indicadores da EAD no contexto da UAB em Alagoas, oferecendo subsídios para análise da oferta de cursos, como também, contribuindo para uma análise no cenário brasileiro do sistema.

\section{PALAVRAS-CHAVE}

Educação a Distância. Ensino Superior. Política da Educação. 


\section{ABSTRACT}

The study investigates the Open University of Brazil (UAB) as a public policy of expansion of higher education in the state of Alagoas, which aims to increase the number of teachers of basic education with higher education, as required by Law of Directives and Bases of National Education and the National Education Plan. Analyzes the profile of UAB students at the Federal University of Alagoas (UFAL). The case study involved collecting data through online questionnaire with students 10 undergraduate courses offered. The results show EAD indicators in the context of UAB in Alagoas, offering subsidies to analyze the offer of courses, as well as contributing to an analysis of the system in the Brazilian scenario.

\section{KEYWORDS}

Distance Education. Higher Education. Education Policy

\section{RESUMEN}

El estudio investiga la Universidad Abierta de Brasil (UAB) como una política pública de la expansión de la educación superior en el estado de Alagoas, que tiene como objetivo aumentar el número de maestros de educación básica con la educación superior, como lo requiere la Ley de Directrices y Bases de la Educación Nacional y el plan Nacional de Educación. Analiza el perfil de los estudiantes de la UAB en la Universidad Federal de Alagoas (UFAL). El estudio de caso implicó la recopilación de datos a través de cuestionario en línea con los estudiantes de 10 cursos de graduación. Los resultados muestran indicadores EAD en el contexto de la UAB, en Alagoas, ofreciendo subsidios para analizar la oferta de cursos, así como contribuir a un análisis del sistema en el escenario brasileño.

\section{PALABRAS CLAVE}

educación a distancia; Enseñanza superior; La política educativa 


\section{INTRODUÇ̧̃̃o}

A Educação a Distância (EAD), modalidade de oferta da educação superior, vem se expandindo consideravelmente desde 2000, de acordo com dados do MEC/INEP em 2013. Do total de 7.305.977 matrículas no ensino superior, 1.153 .572 (84,2\%) estudantes estão na EAD; dos 32.049 cursos de graduação, 1.258 são na modalidade EAD; das 5.068 .142 vagas oferecidas no ensino superior, 1.638.427 (15,8\%) estão na EAD.

Existem 752 cursos EAD em Instituição de Ensino Superior (IES) privadas e 506 em Instituição Pública de Ensino Superior (IPES). Quanto ao vestibular, em 2013 foram inscritos 7.844 .638 no computo geral, sendo 1.429.360 na modalidade EAD.

As regiões Norte e Nordeste são as que apresentam menor número de matrículas na EAD. Na região Norte tem 568.337 estudantes no ensino superior, sendo 24.342 na EAD e na região Nordeste tem-se 1.521.707 no ensino superior e 84.176 na EAD.

Nos últimos dez anos o Brasil tem acompanhado a constituição e crescimento da UAB que, desde 2006, tem se pautado em cinco eixos fundamentais: expansão pública da educação superior, considerando os processos de democratização e acesso; aperfeiçoamento dos processos de gestão das IPES, possibilitando sua expansão em consonância com as propostas educacionais dos estados e municípios; avaliação da educação superior a distância tendo por base os processos de flexibilização e regulação implantados pelo Ministério da Educação (MEC); estímulo à investigação em educação superior a distância no país; e financiamento dos processos de implantação, execução e formação de recursos humanos em educação superior a distância.

No aperfeiçoamento dos processos de gestão das IPES, novos desafios são postos, observando que as concepções de gestão para esta modalidade são baseadas nas experiências administrativas das IPES presenciais, inclusive devido ao fato de que a escolha da Coordenação da UAB nas IES integrantes ao sistema ainda ser realizada a partir da escolha dos reitores, não predominando experiências de profissionais e pesquisadores da área da EAD.

O foco deste estudo foi a análise da oferta de cursos de graduação articulada pela Coordenadoria Institucional de Educação a Distância (CIED) na UFAL, IPES com 17 anos de experiência na oferta de cursos na modalidade a distância.

\section{A UAB: CRIAÇ̃̃O E OBJETIVOS}

A UAB foi criada por meio do Decreto n 5.800 de 8/6/2006, com a finalidade de expandir e interiorizar a oferta de cursos e programas de educação superior no País, com objetivo de: oferecer cursos de licenciatura e de formação inicial e continuada de professores da educação básica; cursos superiores para capacitação de dirigentes, gestores e trabalhadores em educação básica dos Estados, do Distrito Federal e dos Municípios; cursos superiores nas diferentes áreas do conhecimento; ampliar 
o acesso à educação superior pública; reduzir as desigualdades de oferta de ensino superior entre as diferentes regiões do País; estabelecer amplo sistema nacional de educação superior à distância; e fomentar o desenvolvimento institucional para a modalidade de EAD, pesquisa em metodologias inovadoras de ensino superior apoiadas nas Tecnologias da informação e comunicação (TIC).

A UAB é um sistema integrado por IPES, inicialmente sob a regulação da extinta Secretaria de Educação a Distância (SEED/MEC) e desde 2011 sob regulação da Coordenação de Aperfeiçoamento de Pessoal de Nível Superior (CAPES), que oferece cursos de nível superior para camadas da população que têm dificuldade de acesso à formação universitária, por meio da EAD. Os professores que atuam na Educação Básica têm prioridade de formação, seguidos dos dirigentes, gestores e trabalhadores em educação básica dos estados, municípios e do Distrito Federal.

A execução das ações da UAB é realizada por meio de projetos, com data de inicio e término, financiados pela CAPES/MEC e todos os sujeitos que atuam na gestão e docência são beneficiários de bolsas da CAPES. Os projetos estão vinculados à uma matriz pedagógica registrada no Sistema de Acompanhamento da UAB (SISUAB). Os projetos financiados pela Capes são orçados para execução dentro do ano em curso, o que envolve pagamentos de bolsas, serviços prestados, passagens e diárias nacionais. Uma vez que o Sistema funciona com bolsas, quando as atividades forem suspensas as bolsas serão da mesma forma, pois nos Termos de Compromisso assinados pelos bolsistas o pagamento está vinculado a realização das atividades previstas nos mesmos.

A EAD só passou a existir como modalidade de ensino oficial para a graduação em 1996, com a LDBEN e sua consolidação ocorreu na primeira década dos anos 2000, tendo como marco a criação da UAB em 2006; Sistema gerido pelo Governo Federal para a oferta de cursos de graduação a distância nas IPES.

A UAB iniciou com a oferta do Curso piloto de Administração a Distância, financiado pelo Fundo das Estatais, por meio do Banco do Brasil. O MEC, com a finalidade de atender à demanda das empresas estatais em termos de qualificação dos seus servidores públicos, propôs, em parceria com 25 universidades públicas, a criação de um curso de Graduação em Administração, na modalidade à distância. Instalado em junho de 2006, o projeto iniciou as atividades em 174 polos. A opção por essa modalidade deve-se não só à necessidade de se atender alunos residentes em regiões que não possuam ensino superior, mas, também, profissionais em serviço que necessitam formação em nível universitário. 0 curso ofereceu 500 vagas para o Estado de Alagoas.

Sahb e Silva (2013) defendem que se faz necessário uma formulação e implementação de uma política nacional para incentivo de formação de professores e que a UAB enquanto política nacional sofre por uma falta de articulação e unidade, recebendo críticas, inclusive por todo empreendimento público investido.

A UAB, segundo Costa e Pimentel (2009) tem contribuído para a melhoria e ampliação da oferta de educação superior no Brasil, estabelecendo paradigmas de qualidade na implementação de cursos na EAD, em todas as áreas do conhecimento. Para Pimenta e De Lima Amaral (2014, p. )

os resultados encontrados indicam o crescimento, ao longo do tempo, da formação superior dos professores e a crescente atuação da UAB no país. Podemos encontrar nesse sistema a possibilidade de vencer um dos maiores desafios da educação básica brasileira: 
formar aqueles professores sem diploma superior, com cursos de qualidade, e dar oportunidades de participar da formação continuada.

Segundo as autoras, a UAB objetiva levar a educação superior a pontos do país que estão distantes dos grandes centros universitários, alcançando uma parcela da população historicamente desfavorecidas deste tipo de educação. O Sistema UAB se propõe democratizar e interiorizar o acesso ao ensino superior público, por meio das parcerias formadas entre os entes federados e as IPES.

\section{EDUCAÇÃO A DISTÂNCIA NA UFAL}

A UFAL, credenciada para a oferta da modalidade EAD desde 1998, com a publicação da Portaria $n^{0}$ 2.631, aderiu ao Sistema UAB em 2006. Neste ano na institucionalização da EAD na UFAL começa a se tornar uma realidade, pois a EAD deixa de ser uma ação quase exclusiva do NEAD/Centro de Educação e entra na ordem do dia de várias Unidades Acadêmicas e outras áreas, tendo em vista editais das agências de fomento, da SEED/MEC e do início das discussões da constituição da UAB.

Em 2007, no âmbito do Sistema UAB, surge a possibilidade da UFAL ampliar a oferta de novos cursos na modalidade à distância. A Seed/MEC lança Edital para fomentar o Sistema UAB, articulando e integrando experimentalmente IFES, municípios e estados, visando à democratização, expansão e interiorização da oferta do ensino superior público e gratuito no país. Além de ações de ensino, o edital previa o desenvolvimento de projetos de pesquisa e de metodologias inovadoras de ensino, preferencialmente na área de formação inicial e continuada de professores da educação básica.

Neste edital os municípios e estados apresentaram propostas de polos municipais de apoio presencial para ensino superior à distância e as IPES apresentaram propostas de cursos superiores na modalidade de EAD, a serem ofertados nos polos de apoio presencial.

As IPES, atendendo a este edital, apresentaram projetos de cursos superiores na modalidade de EAD, individual ou coletivamente organizados (em consórcios). Cada proposta de curso precisava apresentar: descrição do curso a ser ofertado e número de vagas; cronograma de execução do curso proposto, prevendo as etapas de aprovação interna na IPES, bem como os prazos para sua implementação; descrição das necessidades específicas relativas ao polo de apoio presencial; indicação do quantitativo de polos e suas localizações, incluindo detalhamento das regiões e localidades preferenciais de abrangência; descrição dos recursos humanos (corpo docente específico para EAD e tutores presenciais); detalhamento dos orçamentos estimados e cronograma de desembolso.

As Unidades Acadêmicas da UFAL tomaram conhecimento do referido Edital e se articularam via Comitê Gestor de EAD, criada pela Portaria Reitoral n 847/2006, coordenado pela Vice-Reitoria para elaborarem propostas de cursos e articularem ações com possíveis polos de EAD junto às prefeituras do estado de Alagoas. O Centro de Educação, Instituto de Física e Instituto de Computação, encaminharam por meio do Comitê Gestor de EAD, os projetos dos cursos de bacharelado em Sistemas de 
Informação e das licenciaturas em Pedagogia e Física. Encaminharam solicitações de polos às prefeituras de Maceió, Olho D’Água das Flores, Santana do Ipanema, Maragogi e Porto Calvo.

Nesse Edital, a UFAL teve projetos aprovados com 50 vagas cada curso para cada polo de EAD. Os projetos de polos de apoio presencial e cursos aprovados com previsão de início de funcionamento para setembro de 2007, foram: Sistema de Informação Bacharelado - polos de Maragogi, Olho D’Água das Flores, Santana do Ipanema e Maceió; Pedagogia Licenciatura - polos de Maragogi, Olho D’Água das Flores, Santana do Ipanema e Maceió; Física Licenciatura - polos de Olho D’Água das Flores, Santana do Ipanema e Maceió; Administração Bacharelado - polo de Maragogi e Olho D’Água das Flores.

Atualmente a UFAL oferta onze cursos de licenciatura do Sistema UAB: Física, Matemática, Pedagogia, Letras Espanhol, Letras Inglês, Letras Português, Química, Ciências Sociais e os bacharelados em Sistema de Informação e Administração Pública. Também são ofertados os Cursos de Especialização a Distância do Programa Nacional de Formação em Administração Pública (PNAP/CAPES): Gestão Pública, Gestão em Saúde e Gestão Pública Municipal e as especializações de formação continuada de professores: Mídias em Educação, Ensino de Geografia, Tecnologia da Informação para Educadores e Estratégias Didáticas para Educação Básica com o uso de TIC.

Esse cenário se amplia cada vez mais com a indução da oferta de cursos de licenciatura da UFAL não contemplados na oferta na modalidade a distância, como Educação Física, Ciências Biológicas, Filosofia, Artes, História, além dos cursos de Mestrado Profissionalizantes na modalidade semipresencial e a distância induzidos pela Capes, como o caso do Mestrado Profissional em Matemática em Rede Nacional (PROFMAT), Programa de Mestrado Profissional em Letras (PROFLETRAS) e o Mestrado Profissional em Administração Pública (PROFIAP).

\section{METODOLOGIA}

A metodologia envolveu estudo do perfil dos alunos da UAB na UFAL a partir da coleta de dados por meio de questionário on-line junto aos estudantes de onze cursos, para análise dos indicadores: idade, sexo, curso matriculado, polo vinculado, vínculo com o mercado de trabalho, vínculo com o setor público ou privado, atuação no magistério da educação básica, relação curso matriculado e área atual de atuação e situação acadêmica anterior.

A coleta de dados foi realizada em maio de 2015, por meio de questionário on-line disponível em http://migre.me/qbBoC para que os estudantes do Sistema UAB da UFAL respondessem as questões do estudo. Visando uma maior participação, foi encaminhado aos Coordenadores de Curso uma mensagem via e-mail solicitando que instruíssem os estudantes a responderem ao questionário no período indicado pelos pesquisadores.

Os resultados mostram indicadores da EAD no contexto da UAB em Alagoas, oferecendo subsídios para análise dos indicadores investigados neste estudo. 
Tabela 1 - Curso em que o estudante está matriculado

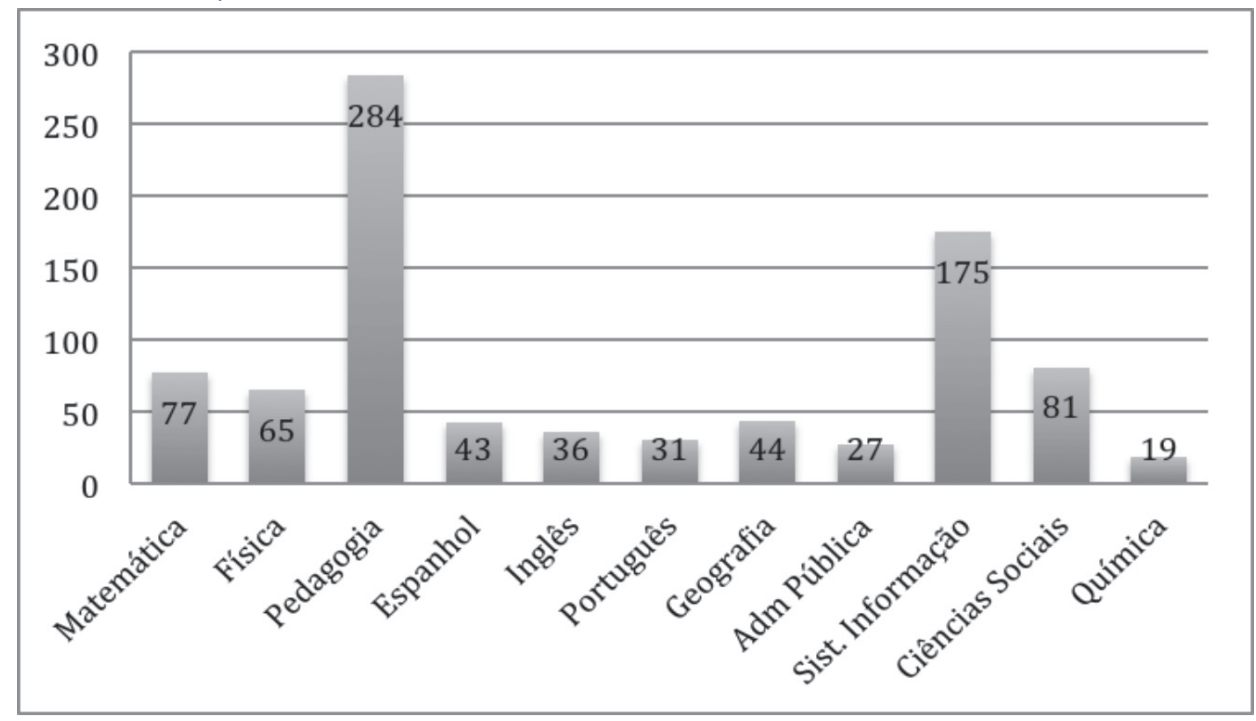

Fonte: Dados da pesquisa (2015);

O questionário foi respondido por 881 estudantes dos onze cursos de graduação da UAB/Ufal (TABELA 1), destes, $58,56 \%$ afirmaram ser do sexo masculino e $41,43 \%$ do sexo feminino.

Os resultados mostram uma realidade significativa da indução e oferta do ensino superior pela UAB/Ufal. A Tabela 1 apresenta o quantitativo de respondentes de cada curso, justificando-se uma maior participação dos cursos de Pedagogia e de Sistemas de Informação pelo maior número de matriculados nestes dois cursos. Registra-se também uma maior concentração de vagas ofertadas em cursos de licenciatura (nove cursos), visando atender a prioridade do Sistema UAB de formação de professores para a educação básica.

As respostas sobre qual polo o estudante estava vinculado mostra que $23,38 \%$ estão vinculados ao polo da capital alagoana, conforme a Tabela 2. Esta realidade comprova o objetivo da UAB em seu princípio de interiorização do ensino superior, constatando-se que $75 \%$ dos estudantes estão matriculados em polos situados no interior do estado, disseminando a oferta de vagas em 10 polos de apoio presencial.

Estes dados, analisados a partir das metas definidas pelo Plano Nacional de Educação (PNE) (BRASIL, 2014), indicam que a UAB já atende a meta 12 apresentada na legislação. Entretanto, como preconiza a Lei $n^{0}$ 13.005/2014, estes índices precisam ser intensificados.

Conforme o PNE (2014-2024) o Brasil precisa atingir algumas metas e estratégias para assegurar uma educação de qualidade para todos. No referente aos objetivos da UAB, observa-se que o Sistema, por meio de seus cursos distribuídos nos mais diversos polos de apoio presencial, pode atender 0 disposto na meta 12 e suas estratégias, a saber: 
Meta 12 - Elevar a taxa bruta de matrícula na educação superior para 50\% e a taxa liquida para $33 \%$ da população de 18 a 24 anos, assegurando a qualidade da oferta.

12.2) Ampliar a oferta de vagas por meio da expansão e interiorização da rede federal de educação superior, da Rede Federal de Educação Profissional, Científica e Tecnológica e do Sistema Universidade Aberta do Brasil, considerando a densidade populacional, a oferta de vagas públicas em relação à população na idade de referência e observadas as características regionais das micro e mesoregiões definidas pelo IBGE, uniformizando a expansão no território nacional.

12.3) Elevar gradualmente a taxa de conclusão média dos cursos de graduação presenciais nas universidades públicas para $90 \%$, ofertar das vagas em cursos noturnos e elevar a relação aluno: professor para 18, mediante estratégias de aproveitamento de créditos e inovações acadêmicas que valorizam a aquisição de competências de nível superior.

12.4) Fomentar a oferta de educação superior pública e gratuita prioritariamente para a formação de professores para a educação básica, sobretudo nas áreas de ciências e matemática, bem como para atender o déficit de profissionais em áreas específicas.

Tabela 2 - Polo em que o estudante está vinculado

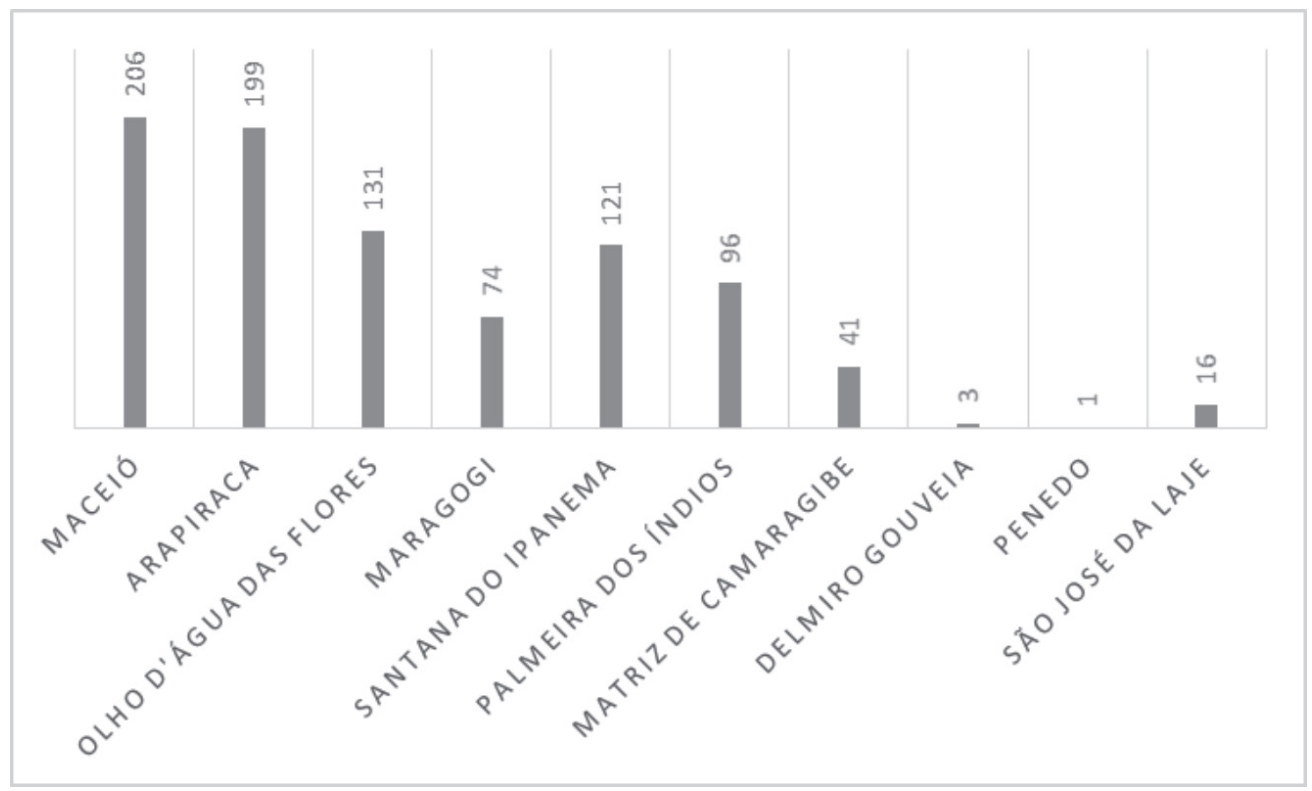

Fonte: Dados da pesquisa (2015);

Dos respondentes, 603 estudantes responderam positivamente quando questionados se já se encontram no mercado de trabalho, correspondendo a 68,45\%. Destes estudantes, 415 indicam estar no setor público e 211 no setor privado. 
Quando questionados se são professores, 305 respondentes indicaram positivamente, correspondendo a 35\% (GRÁFICO 1), e destes, 290 atuam na Educação Básica (correspondente a 95,08\% dos que responderam positivamente).

Gráfico 1 - Estudantes da UAB que já são professores

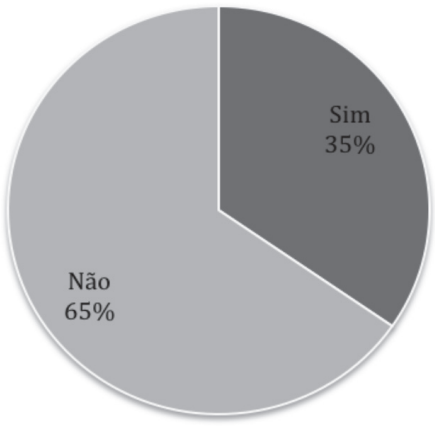

Fonte: Dados da pesquisa (2015).

Nestes dados, detecta-se que a prioridade do Sistema UAB da capacitação de professores da educação básica com a oferta de cursos de licenciatura e de formação continuada não está sendo plenamente realizada, quando a oferta das vagas tem sido preenchida por um outro público.

Gráfico 2 - Relação entre curso e atuação como professor

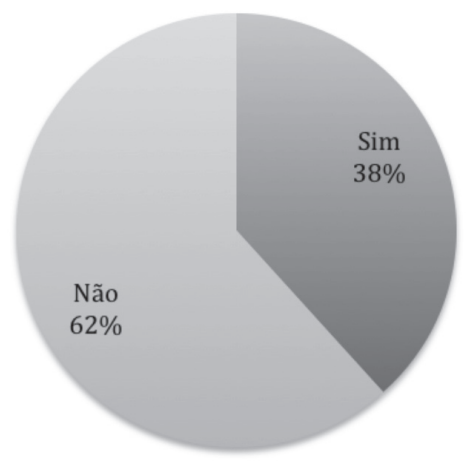

Fonte: Dados da pesquisa (2015).

Foi questionado se o curso que o estudante está realizando pela UAB/Ufal é na área de sua atividade como professor. 0 Gráfico 2, 38\% indicam positivamente, o que também vai de encontro a prioridade do Sistema UAB, quando se busca a formação de professores que estão na rede de ensino básico, mas sem a devida formação em nível superior. 
Gráfico 3 - Já possui curso superior

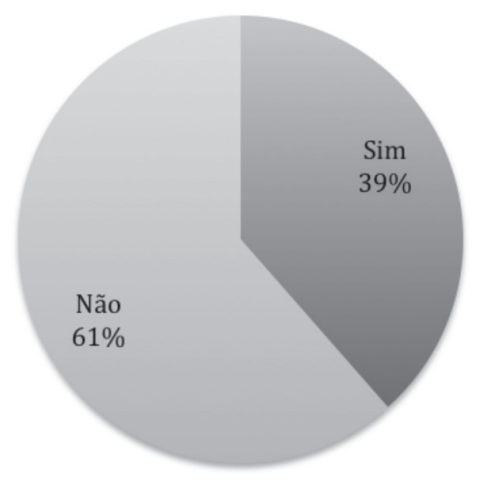

Fonte: Dados da pesquisa (2015).

Na $11^{\text {a }}$ questão foi perguntado se o estudante já possuia uma graduação, $39 \%$ dos respondentes indicaram que já possuem um curso superior (GRÁFICO 3), sendo que 192 cursaram em instituição pública e 123 em instituição privada (GRÁFCO 4).

Em relação ao resultados destes dados, observa-se que o Sistema UAB poderia atender a Meta 14 do PNE (BRASIL, 2014) aumentando o número de ofertas de cursos stricto sensu por meio da EAD (estratégia 14.4 do PNE), atingindo os índices apresentados na legislação de sessenta mil mestres e vinte e cinco mil doutores, anualmente. Como uma parte significativa dos que estão matriculados (39\%) já possuem graduação, poderiam estar aprofundando e ampliando seu conhecimento e fortalecendo a pesquisa científica, potenciando a pesquisa científica, a inovação e a promoção da formação de recursos humanos.

Gráfico 4 - Instituição que fez o curso superior anterior

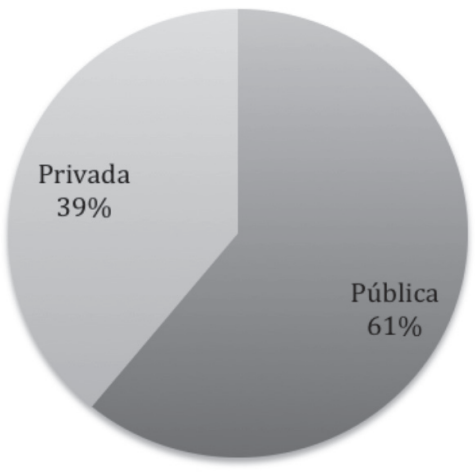

Fonte: Dados da pesquisa (2015); 
Quando questionados sobre em que especificidade de instituição realizaram a graduação anterior, $61 \%$ dos estudantes que já possuem esta formação indicam que estudaram em uma IPES (GRÁFICO 4), demonstrando o alcance do setor público na oferta de cursos de graduação, ao tempo que revela que mais de $50 \%$ das vagas atualmente ofertadas pela UAB poderiam estar sendo preenchidas por pessoas que ainda não têm uma formação anterior. Estes dados também apontam para a realidade de um número expressivo de pessoas que buscam uma mudança em seu perfil acadêmico em vistas de uma mudança profissional.

\section{CONSIDERAÇÕES FINAIS}

A educação a distância tem favorecido o desenvolvimento de diversas atividades, nas mais diferentes categorias. Neste sentido, a expansão e democratização do acesso a informação tem se realizado junto a iniciativas.

$\mathrm{Na}$ análise dos dados deste estudo, considera-se que a oferta de cursos por meio do Sistema UAB pela Ufal, tem atendido aos propósitos e objetivos do Sistema, como também algumas das estratégias das metas 12 do PNE, mas que podem ser ampliadas e intensificadas, especificamente na oferta de vagas nos cursos de matemática e física e nos polos mais distantes dos campus da universidade.

\section{REFERÊNCIAS}

BRASIL. Decreto n 5.800, de 8 de junho de 2006. Dispõe sobre o Sistema Universidade Aberta do Brasil - UAB. Diário Oficial da União, Brasília, 9 jun. Seção 1, p. 4. 2006.

BRASIL. Lei n 13.005, de 25 de junho de 2014. Aprova o Plano Nacional de Educação - PNE e dá outras providências. Diário Oficial da União, Seção 1, Edição Extra - 26/6/2014, p. 1. 2014.

COSTA, C.; PIMENTEL, N. O Sistema Universidade Aberta do Brasil na consolidação da oferta de cursos superiores a distância no Brasil. ETD - Educação Temática Digital, Campinas, v. 10, n. 2, p. 71-90, jun. 2009.

INEP - Instituto Nacional de Estudos e Pesquisas Educacionais Anísio Teixeira. Censo de Educação Superior. Brasília: INEP, 2014.

PIMENTA, D.; DE LIMA AMARAL, E. Estudo sobre o Sistema Universidade Aberta do Brasil (UAB) e a formação de professores da educação básica, 2003, 2005 e 2011. In.: DE LIMA AMARAL, E.;

GONÇALVES, G.; FAUSTINO, S. (org.). Aplicações de técnicas avançadas de avaliação de políticas públicas [recurso eletrônico]. Fino Traço, Belo Horizonte, p. 113-152, 2014. Disponível em http:// www.sne.gob.sv/media/3512/avaliacao.pdf\#page=113. Acesso: 20 maio 2015. 
SAHB, W.; SILVA, A. Política nacional de formação de professores: o Sistema UAB e os cursos de licenciatura da Universidade Federal de Lavras. X Congresso Brasileiro de Ensino Superior a Distância Belém, 10, 2013. Anais [...], 11-13 de junho de 2013. Disponível em: http://www.aedi.ufpa.br/esud/trabalhos/ poster/AT1/114126.pdf. Acesso em: 10 jun. 2015.

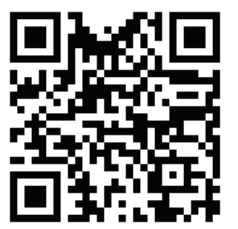

1 Doutor em Educação (UFAL); Mestre em Educação pela Universidade Federal de Alagoas (2010); Especialista em Tecnologias em Educação e Docência do Ensino Superior; Graduado em Pedagogia (Licenciatura) ; Foi professor de escolas particulares, tutor do programa de formação continuada - Secretaria de Educação a Distância - MEC, professor tutor 1 da Universidade Tiradentes e professor do Governo do Estado de Alagoas; Tem experiência na área de Educação, com ênfase em Ensino-Aprendizagem, atuando principalmente nos seguintes temas: aprendizagem, educação on-line, webquest, tutoria e avaliação; Atualmente é professor adjunto da Universidade Federal de Alagoas; Foi Vice-coordenador da Coordenadoria Institucional de Educação a Distância e Coordenador Adjunto da UAB/UFAL. E-mail: prof.fernandoscp@gmail.com

2 Professor Titular da Universidade Federal de Alagoas UFAL. E-mail: luispaulomercado@gmail.com

\section{Como citar este artigo:}

PIMENTEL, Fernando Silvio Cavalcante; MERCADO, Luís Paulo Leopoldo. A política de expansão do ensino superior por meio da UAB em Alagoas. Interfaces Científicas - Educação, Aracaju- SE- BRASIL, v. 7, n. 3, 2019, p.139-154. DOI: 0000000000

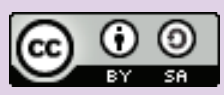

Este artigo é licenciado na modalidade acesso abertosob a Atribuição-Compartilhalgual CC BY-SA

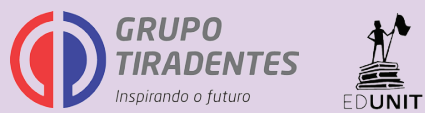

